\title{
Virtual Surgical Fellowship Recruitment During COVID-19 and Its Implications for Resident/Fellow Recruitment in the Future
}

\author{
Charles C. Vining, MD ${ }^{1}$, Oliver S. Eng, MD ${ }^{1}$, Melissa E. Hogg, MD, MS ${ }^{2}$, Darryl Schuitevoerder, MBBS ${ }^{1}$, \\ Rebecca S. Silverman, BA ${ }^{1}$, Katharine A. Yao, $\mathrm{MD}^{2}$, David J. Winchester, $\mathrm{MD}^{2}$, Kevin K. Roggin, $\mathrm{MD}^{1}$, \\ Mark S. Talamonti, $\mathrm{MD}^{2}$, Mitchell C. Posner, MD ${ }^{1}$, Kiran K. Turaga, MD, MPH ${ }^{1}$, and Jennifer Tseng, MD ${ }^{1}$ \\ ${ }^{1}$ Department of Surgery, The University of Chicago Medicine, Chicago, IL; ${ }^{2}$ Department of Surgery, NorthShore \\ University Health System, Evanston, IL
}

\begin{abstract}
Background. The COVID-19 pandemic has overlapped with the scheduled interview periods of over 20 surgical subspecialty fellowships, including the Complex General Surgical Oncology (CGSO) fellowships in the National Resident Matching Program and the Society of Surgical Oncology's Breast Surgical Oncology fellowships. We outline the successful implementation of and processes behind a virtual interview day for CGSO fellowship recruitment after the start of the pandemic.

Methods. The virtual CGSO fellowship interview process at the University of Chicago Medicine and NorthShore University Health System was outlined and implemented. Separate voluntary, anonymous online secure feedback surveys were email distributed to interview applicants and faculty interviewers after the interview day concluded.

Results. Sixteen of 20 interview applicants $(80.0 \%)$ and 12 of 13 faculty interviewers $(92.3 \%)$ completed their respective feedback surveys. Seventy-five percent (12/16) of applicants and all faculty respondents (12/12) stated the interview process was 'very seamless' or 'seamless'. Applicants and faculty highlighted decreased cost, time savings, and increased efficiency as some of the benefits to virtual interviewing.
\end{abstract}

Conclusions. Current circumstances related to the COVID-19 pandemic require fellowship programs to adapt

(C) Society of Surgical Oncology 2020

First Received: 24 April 2020;

Published Online: 18 May 2020

J. Tseng, MD

e-mail: jtseng@surgery.bsd.uchicago.edu and conduct virtual interviews. Our report describes the successful implementation of a virtual interview process. This report describes the technical steps and pitfalls of organizing such an interview and provides insights into the experience of the interviewer and interviewee.

The COVID-19 pandemic has overlapped with the scheduled interview periods of over 20 surgical subspecialty fellowships, including the Complex General Surgical Oncology (CGSO) fellowships in the National Resident Matching Program and the Society of Surgical Oncology's Breast Surgical Oncology fellowships. Current recommendations for social distancing have prompted universal and obligatory efforts to adjust fellowship recruitment to a virtual format. Published studies of web-based residency and fellowship interviews are limited. ${ }^{1-7}$ Herein, we outline the successful implementation of processes behind a virtual interview day for CGSO fellowship recruitment after the start of the pandemic at the University of Chicago Medicine and NorthShore University Health System. Additionally, we provide survey results from both applicants and faculty interviewers regarding their virtual interview day experiences and outline our recommendations to reimagine recruitment in the era of COVID-19.

\section{THE VIRTUAL FELLOWSHIP INTERVIEW}

Before the Interview Day

Program

- The fellowship program website was relaunched to include (1) links to relevant institutional webpages; and 
(2) short videos with faculty and fellow voiceovers providing personal introductions to program highlights. The website replaced paper materials traditionally handed to applicants and gave applicants additional exposure to faculty members and fellows whom they might not meet through the videoconference interview format (https://voices.uchicago.edu/surgicaloncology).

- Extra program and technical support staff time was reserved for the interview day for immediate troubleshooting assistance.

- A digitized interview ranking sheet was retooled and trialed that collated and visually displayed scoring and narrative commentary results immediately after the interviews were completed.

\section{Faculty Interviewers}

- Faculty interviewers were provided with personalized interview schedules with applicant information. Phone numbers were provided as a backup option for a telephone interview in case the videoconference setup had to be unexpectedly aborted on the interview day.

- Individual password-protected Zoom videoconference rooms were established for each faculty interviewer. Virtual waiting rooms were enabled for added security.

- A test run was held prior to the interview day for faculty interviewers. Volunteers posed as interviewees to troubleshoot potential issues such as locked rooms. Faculty interviewers unfamiliar with hosting Zoom videoconferences were able to practice setting up virtual backgrounds and use host controls.

- Faculty interviewers received a central Zoom videoconference room link for the post-interview debrief and ranking meeting.

\section{Applicants}

- Applicants were emailed personalized interview schedules with each faculty interviewer's individual Zoom videoconference room link, meeting ID, and password. This email also contained a link to the fellowship program website.

- An optional preparatory session for applicants was held via Zoom with the program director and staff. The program director gave an overview of the fellowship program, troubleshooting guidelines for the interview day, and introduced staff members who would serve as points of contact in case of technical difficulties.

\section{Interview Day}

Thirteen faculty members from the University of Chicago Medicine/NorthShore University Health System Complex General Surgical Oncology Fellowship interviewed 20 applicants via a virtual videoconferencing platform over a 4-h time span. Interview schedules were staggered to allow all applicants to meet with the program director for $10 \mathrm{~min}$, institutional leaders for $15 \mathrm{~min}$, and three additional faculty members for $30 \mathrm{~min}$ each. Time gaps were engineered into the interview schedules to allow the faculty to complete the web-based interview ranking sheets and to troubleshoot in the event technical glitches arose. The current CGSO fellows had a separate Zoom videoconference room to field questions, with the ability to offer applicants breakout rooms to speak one-on-one.

One faculty member was delayed in starting two interviews on time due to non-technical issues; however, the interview schedule was built with enough flexibility to facilitate rescheduled interviews with these applicants at a later point in the morning. A post-interview day debrief and ranking videoconference meeting was held immediately after interviews concluded, using summaries of the new digitized interview ranking sheets to guide discussions.

\section{SURVEY ADMINISTRATION AND RESULTS}

Separate voluntary, anonymous online secure feedback surveys were email distributed to interview applicants and faculty interviewers after the interview day concluded. Surveys were a combination of multiple choice and openended questions. Sixteen of 20 interview applicants $(80.0 \%)$ and 12 of 13 faculty interviewers (92.3\%) completed their respective feedback surveys. Institutional Review Board exemption was obtained.

\section{Applicants}

Seventy-five percent (12/16) of applicants stated the interview process was 'very seamless' or 'seamless' and $25.0 \%$ (4/16) were 'neutral' (Fig. 1). The majority of applicants $(12 / 16 ; 75.0 \%)$ had no technical issues. All applicants surveyed $(16 / 16 ; 100 \%)$ received adequate information about the virtual interview process and used the fellowship website to familiarize themselves with the program. Three of the 16 applicants (18.8\%) prepared with a mock virtual interview; 2 of $3(66.7 \%)$ found doing so helpful.

The majority of applicants $(13 / 16 ; 81.3 \%)$ felt they were able to convey themselves 'very well' or 'well' during the Zoom videoconference interviews. All responding applicants $(16 / 16 ; 100 \%)$ reported adequate faculty and fellow 


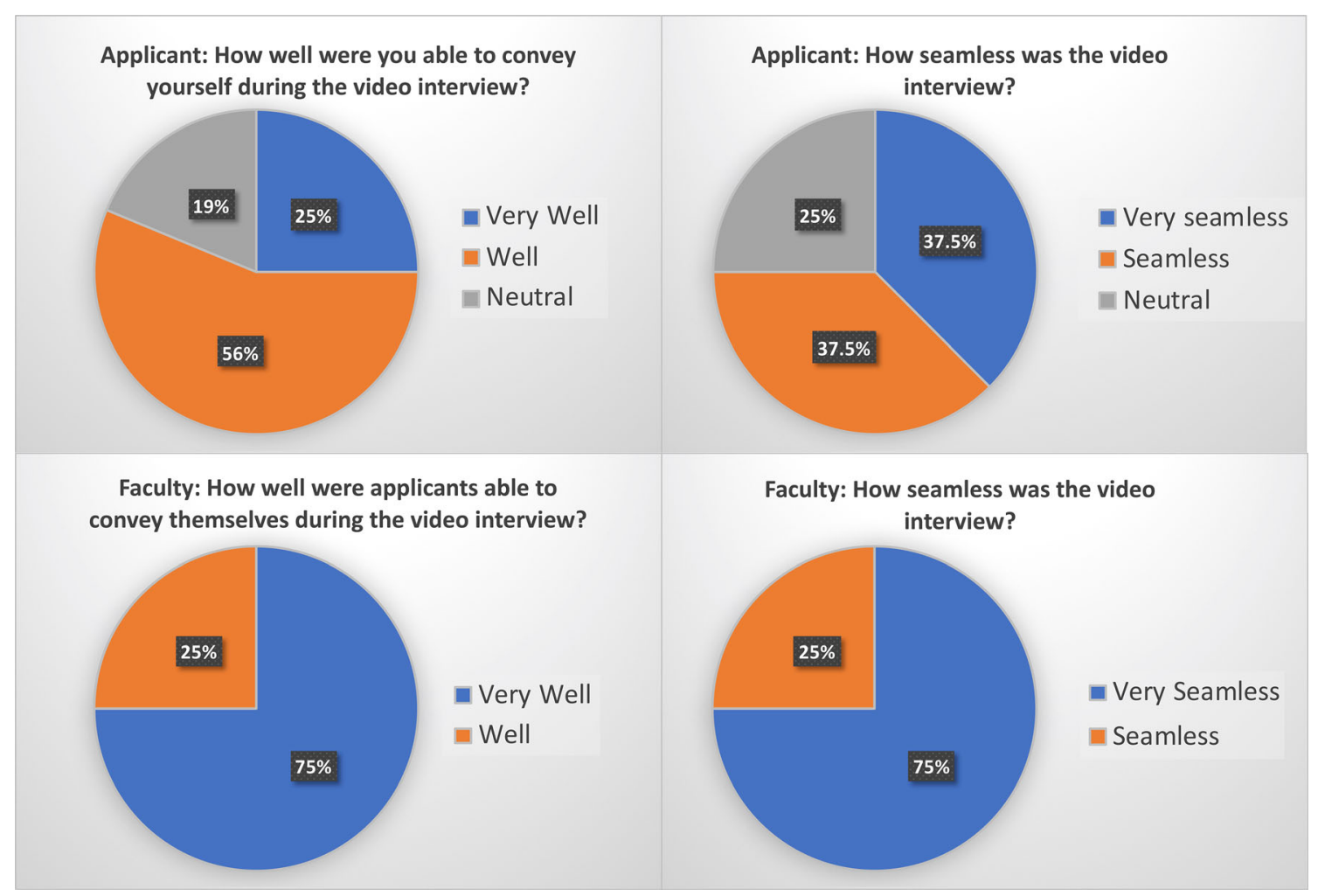

FIG. 1 Applicant and faculty survey responses

accessibility. The vast majority felt comfortable asking questions or making comments during the videoconference interviews $(15 / 16 ; 93.8 \%)$. All applicants reported either a 'very good' or 'good' understanding of the program after the virtual interview day.

Applicants highlighted cost and time savings, increased efficiency, and decreased stress related to travel as some of the benefits to virtual interviewing. Applicants missed seeing the hospital and visiting the fellowship location city. They also commented on wanting a better appreciation of faculty interaction with each other, with fellows, and other staff members. Overall, the majority of applicants expressed a preference for live interviews $(11 / 16 ; 68.8 \%)$.

\section{Faculty Interviewers}

All responding faculty interviewers $(12 / 12 ; 100 \%)$ stated the interview process was 'very seamless' or 'seamless' and felt that the preparatory session was 'very helpful' or 'helpful'. The vast majority of faculty interviewers (11/12; $91.7 \%$ ) believed they received adequate information about the video interview process. All $(12 / 12,100 \%)$ found that applicants were able to convey themselves 'very well' or 'well', and use of the digitized interview ranking sheet was 'very seamless' or 'seamless'.

Faculty interviewers appreciated being able to conduct interviews away from the hospital and highlighted the efficiency and convenience of Zoom videoconference interviews. Faculty interviewers also remarked they regretted applicants did not have a better sense of the hospital campus. They expressed ongoing nervousness about technical issues even though only one faculty interviewer had a temporary technical connectivity problem. Half of the faculty interviewers $(6 / 12 ; 50.0 \%)$ preferred live interviews and one-third $(4 / 12 ; 33.3 \%)$ favored video interviews.

\section{SUMMARY}

Current circumstances related to the COVID-19 pandemic require fellowship programs to adapt and conduct virtual interviews. Our report describes the successful implementation of such a virtual interview process. This report outlines the technical steps and pitfalls of organizing such an interview and provides insights into the experience of the interviewer and interviewee.

Our fellowship interviews used the Zoom videoconference platform. Given our institution's use of this platform for virtual patient care, our technical support staff were easily able to transition Zoom use for educational conferences and interviews. Our fellowship interview day took advantage of Zoom host controls to regulate participant entry into a videoconference and the ability to create breakout rooms. Studies have reported programs utilizing 
other videoconference technology, such as Cisco WebEx, Skype, and FaceTime by Apple, Inc., for virtual interviews. $^{2-4,6,8-10}$ While WebEx requires users to fill out contact and other information for access, Zoom allows users to simply click on a link to enter a videoconference. Zoom permits more group participants than Skype. Similarly, FaceTime is limited in the number of participants and is only available on Apple devices.

Virtual interviews offer advantages of reduced stress from travel, improved efficiency, and the ability to express oneself almost similarly to an in-person interview. Faculty also echoed the enhanced efficiency and convenience. Oladeji et al. found that the mean total cost for orthopedic fellowship match interviews was US\$5875. ${ }^{11}$ Watson et al. reported that $62.3 \%$ of general surgery residents spent over US $\$ 4000$ and $21.7 \%$ spent over US $\$ 8000$ for fellowship interviews. ${ }^{12}$ Given the current climate of rising student debt, our forced transition to virtual interviewing during the COVID-19 pandemic permits us to rethink how surgery subspecialties structure recruitment, both now and in the future. This would also improve institutional resources, as a prior survey found that, on average, over US\$8000 is spent by the host program in hard costs. ${ }^{13}$ Additionally, residency programs would be less disrupted by interviewing residents who miss an average of 1 week to 10 days for fellowship interviews and associated travel. ${ }^{11,12}$

Overall, our survey respondents found the virtual videoconference interview process to be seamless and applicants were able to convey themselves well. Notably, however, the surveys showed that live interviews were preferred. Before COVID-19, applicants had the option of visiting programs even if they participated in virtual interviews. This obviated the financial incentive of saved travel costs but was a contingency option if an interviewee felt they needed a more in-depth live impression of a program or wished to bolster his or her candidacy with inperson meetings. ${ }^{8}$ There also remains some concerns about how comparable virtual interviews are to live interviews, as prior publications reported applicants and programs did not always feel interviewees could represent themselves well through videoconference methods. ${ }^{2,4}$ Our survey showed that although in the minority, there were applicants who did not feel they conveyed themselves well during the video interviews.

Nevertheless, this current time period necessitating virtual experiences is a rich opportunity for programs to improve upon fellowship recruitment processes and possibly even how to integrate virtual interviewing into residency recruitment in the future given the improvements in cost, time, and efficiency. Thus, our lessons learned and recommendations for surgical fellowship programs include the following.
- Hold a mock interview day to identify issues related to connectivity and to anticipate questions from faculty members who may be unfamiliar with the videoconference interface and need practice with the technology.

- Design multiple methods for applicants to learn about the program. Examples include adding content to existing websites, narrating videos or podcasts, and organizing an informal night before 'happy hour' with fellows and videoconference open forums during the interview day.

- Applicants appreciate contact with faculty and fellows in individual and group settings. Consider holding a structured introductory session at the beginning of the interview day and include an optional end-of-the-day group question and answer session with faculty, fellows, and other applicants.

- Applicants are interested in the unique physical elements of an institution and its location. Video or live streaming hospital tours may enhance the virtual interview experience.

- Implement virtual interview forms for data collection to electronically collate information.

- Continue to study the virtual interview process to further streamline processes and optimize how applicants can convey to programs their desired best impressions.

FUNDING None.

DISCLOSURES Melissa Hogg: Intuitive - proctor and trainer to an institution special purpose research and education fund.

\section{REFERENCES}

1. Pasadhika S, Altenbernd T, Ober R, et al. Residency interview video conferencing. Ophthalmology. 2012;119:426.

2. Shah SK, Arora S, Skipper B, Kalishman S, Timm TC, Smith AY. Randomized evaluation of a web based interview process for urology resident selection. J Urol. 2012;187(4):1380-4. https://d oi.org/10.1016/j.juro.2011.11.108.

3. Chandler NM, Litz CN, Chang HL, Danielson PD. Efficacy of Videoconference interviews in the pediatric surgery match. $J$ Surg Educ. 2019;76(2):420-6. https://doi.org/10.1016/j.jsurg.20 18.08.010.

4. Healy WL, Bedair H. Videoconference interviews for an adult reconstruction fellowship: lessons learned. J Bone Joint Surg Am. 2017;99(21):e114. https://doi.org/10.2106/jbjs.17.00322.

5. Jones RE, Abdelfattah KR. Virtual Interviews in the Era of COVID-19: A Primer for Applicants. J Surg Educ. 2020. https://d oi.org/10.1016/j.jsurg.2020.03.020.

6. Day RW, Taylor BM, Bednarski B, et al. Virtual interviews for surgical training program applicants during COVID-19: lessons learned and recommendations. Ann Surg. https://journals.lww.c om/annalsofsurgery/Documents/Virtual\%20Interviews $\% 20$ for $\% 2$ 0Surgical\%20Training\%20Program\%20Applicants\%20.pdf. (in press).

7. Association of American Medical Colleges. Virtual interviews: applicant preparation guide. Available at: https://www.aamc.org/ 
system/files/2020-05/Virtual_Interview_Tips_for_Applicants_05 072020.pdf (2020). Accessed 7 May 2020.

8. Pasadhika S, Altenbernd T, Ober RR, Harvey EM, Miller JM. Residency interview video conferencing. Ophthalmology. 2012;119(2):426-e5. https://doi.org/10.1016/j.ophtha.2011.09. 032 .

9. Pourmand A, Lee H, Fair M, Maloney K, Caggiula A. Feasibility and usability of tele-interview for medical residency interview. West J Emerg Med. 2018;19(1):80-6. https://doi.org/10. 5811/westjem.2017.11.35167.

10. Vadi MG, Malkin MR, Lenar J, et al. Comparison of web-based and face-to-face interviews for application to an anesthesiology training program: a pilot study. Int J Med Educ. 2016;7:102-8.

11. Oladeji LO, Pehler SF, Raley JA, Khoury JG, Ponce BA. Is the orthopedic fellowship interview process broken? A survey of program directors and residents. Am J Orthop (Belle Mead NJ). 2015;44(11):E444-53.

12. Watson SL, Hollis RH, Oladeji L, Xu S, Porterfield JR, Ponce BA. The burden of the fellowship interview process on general surgery residents and programs. J Surg Educ. 2017;74(1):167-72. https://doi.org/10.1016/j.jsurg.2016.06.008.

13. Gardner AK, Smink DS, Scott BG, Korndorffer JR Jr, Harrington D, Ritter EM. How much are we spending on resident selection? J Surg Educ. 2018;75(6):e85-90. https://doi.org/10.1016/j. jsurg.2018.10.001.

Publisher's Note Springer Nature remains neutral with regard to jurisdictional claims in published maps and institutional affiliations. 